\title{
KALIMAT TANYA DALAM PERSIDANGAN DI PENGADILAN NEGERI BANDA ACEH
}

\section{INTERROGATIVE SENTENCES OF TRIAL IN BANDA ACEH DISTRIC COURT}

\author{
Rahmad Nuthihar', Tara Astika Bangun², Wahdaniah ${ }^{3}$ \\ ${ }^{1}$ Akademi Komunitas Negeri Aceh Barat \\ ${ }^{2}$ Guru SMP Negeri 2 Langsa \\ ${ }^{3}$ Politeknik Negeri Lhokseumawe \\ rahmad.nuthihar@gmail.com \\ Naskah diterima tanggal 22 Juni 2018 \\ Naskah direvisi terakhir tanggal 6 Desember 2019
}

\begin{abstract}
This study examines the use of interrogative sentences in trials at the Banda Aceh District Court. The trial in principle is an activity to obtain and prove the information being tried. Therefore, the judge as the person in charge of examining and adjudicating cases uses question sentences to obtain information as clearly as possible. The results of this study conclude that the types of question sentences contained in the trials at the Banda Aceh District Court are, partial sentences, total sentences, rhetorical sentences, and subtle sentences. Furthermore, the question sentence function is a representative and directive function.
\end{abstract}

Keywords: question sentence, legal language, court

\begin{abstract}
Abstrak
Penelitian ini mengkaji tentang penggunaan kalimat tanya dalam persidangan di Pengadilan Negeri Banda Aceh. Persidangan pada prinsipnya merupakan kegiatan untuk memperoleh dan membuktikan informasi yang disidangkan. Oleh karena itu, hakim selaku orang yang bertugas memeriksa dan mengadili suatu perkara menggunakan kalimat tanya untuk memperoleh infomrasi sejelas-jelasnya. Hasil penelitian ini menyimpulkan bahwa jenis kalimat tanya yang terdapat dalam persidangan di Pengadilan Negeri Banda Aceh yaitu, kalimat parsial, kalimat total, kalimat retorik, dan kalimat tersamar. Selanjutnya, fungsi kalimat tanya adalah fungsi represntatif dan direktif.

Kata kunci: kalimat tanya, bahasa hukum, pengadilan.
\end{abstract}

\section{PENDAHULUAN}

Bahasa hukum yang digunakan di Indonesia merupakan bahasa Indonesia yang di dalamnya dominan terdapat bahasa asing seperti bahasa Belanda. Hal itu disebabkan Indonesia merupakan daerah jajahan Belanda sehingga dalam perumusan bahasa hukum masih sangat dipengaruhi oleh kosakata bahasa Belanda. Selain itu, bahasa hukum yang terdapat Indonesia masih mempertahankan istilah asing disebabkan oleh Kamus Besar Bahasa Indonesia (KBBI) tidak dapat menjelaskan secara tepat makna dari kosakata tersebut (Nasution \& Sri, 2001:65).

Dalam kehidupan nyata, bahasa hukum dipakai oleh praktisi yang bergerak di bidang hukum seperti panitera yang tugasnya membuat naskah putusan. Begitu juga dengan jaksa yang membuat berita acara dengan menggunakan bahasa Indonesia ragam bahasa hukum. Bahasa hukum pada prinsipnya terdiri atas empat karakteristik (Nasution \& Sri 2001: 59-69), sedangkan Nuthihar \&Iskandar (2015) dari keempat karakteristik tersebut dapat dirincikan lagi menjadi tujuh. Kedua pendapat tersebut hampir sama dengan 
pernyataan Burukina (2012) yang merincikan lebih detail bahwasanya bahasa hukum terdiri atas 13 karakteristik.

Bahasa hukum ragam lisan berbeda dengan bahasa hukum tulisan. Bahasa hukum yang terdapat dalam naskah putusan pengadilan ataupun surat dakwaan sering dibuat bertele-tele dengan komposisi kalimat yang diulang-ulang. Hal itu membuat bahasa hukum sulit dimengerti dan tidak lugas (Harjanti, 2010), sehingga Myška et al (2012) menyarakan agar bahasa hukumdibuat simpel. Bahasa hukum berupa lisan yang terdapat di dalam persidangan umumnya merupakan kalimat tanya karena dalam persidangan hakim berusaha memperoleh informasi secara jelas dari terdakwa ataupun saksi dalam suatu perkara.

\section{KERANGKA TEORETIS Tindak Tutur Ilokusi}

Tindak ilokusi memiliki maksud yang lebih luas daripada tindak lokusi karena tidak hanya sekedar tuturan yang menyampaikan informasi, tetapi lebih dari itu. Umar (2011:140) menjelaskan bahwa sebuah tuturan, selain berfungsi mengatakan atau menginformasikan sesuatu, juga berfungsi melakukan sesuatu. Bila hal ini terjadi, tindak tutur yang terbentuk adalah tindak ilokusi. Tindak ilokusi disebut sebagai the act of doing something (seni melakukan sesuatu).

Tindak ilokusi dapat berupa kalimat performatif. Seperti yang diutarakan Chaer dan Leonie (2004:53) bahwa tindak tutur ilokusi adalah tindak tutur yang biasanya diidentifikasikan dengan kalimat performatif yang eksplisit. Tindak tutur ilokusi ini biasanya berkenaan dengan pemberian izin, mengucapkan terima kasih, menyuruh, menawarkan, dan menjanjikan. Sama halnya dengan pendapat Chaer dan Leoni, Yule (2014:84) juga mengemukakan bahwa tindak ilokusi ditampilkan melalui penekanan komunikatif suatu tuturan. Kita mungkin bertutur untuk membuat suatu pernyataan, tawaran, penjelasan, atau maksud-maksud komunikatif lainnya.

\section{Fungsi Tindak Tutur Ilokusi}

Tindak tutur ilokusi terbagi menjadi beberapa jenis. Menurut Searle (dalam Leech, 2011), pada tingkatan yang paling umum, fungsi-fungsi ilokusi dapat diklasifikasikan menjadi empat jenis sesuai dengan hubungan fungsi-fungsi tersebut dengan tujuan-tujuan sosial berupa pemeliharaan perilaku yang sopan dan terhormat.

(a) Kompetitif (competitive): tujuan ilokusi bersaing dengan tujuan sosial, misalnya memerintah, meminta, menuntut, mengemis.

(b) Menyenangkan (convival): tujuan ilokusi sejalan dengan tujuan sosial, misalnya menawarkan, mengajak/mengundang, menyapa, mengucapkan terima kasih, mengucapkan selamat.

(c) Bekerja sama (collaborative): tujuan ilokusi tidak menghiraukan tujuan sosial, misalnya menyatakan, melapor, mengumumkan, mengajarkan.

(d) Bertentangan (conflictive): tujuan ilokusi bertentangan dengan tujuan sosial, misalnya mengancam, menuduh, menyumpahi, memarahi (hlm 161-162).

Sehubungan dengan itu, Searle (dalam Leech, 2011:163-166) menggolong tindak tutur ilokusi ke dalam lima bentuk tuturan yang masing-masing memiliki fungsi komunikatif. Kelima jenis tindak tutur ilokusi tersebut, yaitu:

(1) Tindak tutur asertif

Searle mengemukakan bahwa tindak tutur asertif adalah tindak tutur yang mengikat penuturnya kepada kebenaran proposisi atas hal yang dikatakannya. Berdasarkan fungsinya, Wijana (dalam Chaer dan Agustina, 2010:18) menyebutkan bahwa asertif atau representatif yang berfungsi untuk menguatkan, menduga, menegaskan, dan mengumumkan.Martinich $\quad$ (1996:147) menambahkan fungsi tindak tutur ini, meliputi tuturan menyatakan, melaporkan, memprediksi, menyebutkan, dan menunjukkan.

(2) Tindak tutur direktif

Kategori tindak tutur direktif yang dikemukakan oleh Austin adalah tindak eksersitif (exercitives utterances). Tindak 
tutur eksersitif merupakan tindak tutur yang menyatakan perjanjian, nasihat, peringatan, dan sebagainya. Verba yang menandainya antara lain mewariskan, menunjuk, menyatakan, membatalkan perintah (lampau), memperingatkan, menurunkan pangkat (Austin, 1962: 150163).

(3) Tindak tutur komisif

Yule (2014:94) menyatakan bahwa tindak tutur komisif adalah tindak tutur yang dipahami oleh penutur untuk mengikatkan dirinya terhadap tindakan di masa yang akan datang. Wijana menyatakan bahwa tindak tutur komisif memiliki fungsi untuk melakukan sesuatu misalnya besumpah atau berjanji (Chaer dan Agustina, 2010:18). Lebih jelasnya, tindak tutur komisif ini meliputi tuturan berjanji, bersumpah, berkaul, menawarkan, menyatakan kesanggupan, dan mengancam (Martinich, 1996: 147).

(4) Tindak tutur ekspresif

Tindak tutur ekspresif dalam kategori Austin masuk ke dalam tindak tutur behafitif (behabitives utterances). Tindak tutur behafitif adalah reaksi-reaksi terhadap kebiasaan dan keberuntungan orang lain dan merupakan sikap serta ekspresi seseorang terhadap kebiasaan orang lain. Verba yang menandai tindak tutur ini misalnya tuturan meminta maaf, berterima kasih, bersimpati, menantang, mengucapkan salam, mengungkapkan rasa kecewa, menungkapkan rasa jengkel, mengucapkan selamat (Austin, 1962: 150-163).

(5) Tindak tutur deklaratif

Leech (2011:165) mengemukakan bahwa tindak tutur deklarasi ialah tindak tutur yang dilakukan penuturnya dengan maksud untuk menciptakan hal (status, keadaan, dan sebagainya) yang baru. Tindak tutur deklarasi meliputi tuturan mengundurkan diri, membaptis, memecat, memberi nama, menjatuhkan hukuman, mengucilkan/membuang, mengangkat (pegawai), dan sebagainya (Leech, 2011:165).

\section{Kalimat Tanya}

Kalimat tanya adalah kalimat yang dituturkan dengan harapan lawan tuturmerespon dengan memberi jawaban atasapa yang ditanyakan (Moeliono, dkk1988). Selain untuk menanyakan tentang sesuatu, kalimat tanya juga berfungsi untuk menyatakan berbagai hal. Dari penelitian ditemukan bahwa kalimat tanya bahasa Indonesia dapat memasuki berbagai klas atau jenis tindak tutur. Sebuah kalimat tanya ada kalanya dapat menyatakan lebih dari satu macam fungsi. Misalnya, selain menyatakan pelarangan, kalimat tanya itu juga menyatakan perintah dan di ujung semua itu ada kalanya penutur bermaksud menyatakan kekecewaan atas apa yang dilakukan lawan tutur, dengan melihat adanya keragaman fungsi tutur kalimat tanya itu, dapat dipahami bahwa bahasa selain berfungsi imformatif juga menjalankan fungsi ekspresif (Lindawati, 2012:259).

Ramlan (2001:33-34) menjelaskan bahwa kalimat tanya dalam bahasa Indonesia berfungsi untuk menanyakan sesuatu. Kalimat tanya memiliki pola intonasi yang berbeda dengan pola intonasi kalimat berita. Perbedaannya terutama terletak pada nada akhirnya. Pola intonasi kalimat berita bernada akhir turun, sedangkan pola intonasi kalimat tanya bernada akhir naik, dan partikel tanyakah dapat ditambahkan pada bagian kalimat yang ditanyakan kecuali pada subjek. Di samping itu, partikel - kah ada kecederungan untuk meletakkan bagian kalimat yang ditanyakan itu di awal kalimat.

Menurut Irwan (2008), kalimat tanya dalam Bahasa Indonesia memiliki ciri sebagai berikut: (1) intonasi yang digunakan merupakan intonasi tanya, (2) dapat pula mempergunakan partikel tanya -kah, atau apakah, (3) sering mempergunakan kata tanya yang dapat digabung dengan partikel $-k a h$. Kalimat tanya berisi permintaan untuk mendapatkan informasi, klarifikasi dan konfirmasi (hlm. 94-98). Berdasarkan ragam atau jenis kalimat tanya dapat dibagi atas empat yaitu:

(1) Kalimat tanya total, yaitu kalimat tanya yang meminta informasi mengenai 
seluruh isi pertanyaannya (Irwan, 2008:94-98). Ciri-ciri kalimat tanya total adalah: (a) menggunakan partikel $-k a h$, (b) jawaban menggunakan "ya" atau "tidak. Dalam kalimat tanya total, kata apa, apakah, bukankah dan haruskah sebagai pembentuk kalimat tanya selalu terletak di awal kalimat (Ramlan, 2001:35-36). Partikel -kah yang berbentuk klitika dan bersifat manasuka dapat menegaskan kalimat interogratif. Apabila partikel $-k a h$ dipakai dalam kalimat deklaratif, -kah mengubah kalimat tersebut menjadi kalimat interogratif. Apabila dipakai dalam kalimat interogratif sudah ada kata tanya seperti apa, di mana, dan bagaimana, maka $-k a h$ bersifat manasuka, menjadikan kalimatnya lebih formal dan sedikit lebih halus. Apabila dipakai dalam kalimat tidak kata tanya tetapi intonasinya adalah intonasi interogratif, maka -kah akan memperjelas kalimat itu sebagai kalimat interogratif (Alwi, 2003:307-308).

(2) Kalimat tanya parsial, yaitu kalimat tanya parsial adalah kalimat tanya yang hanya meminta informasi sebagian dari pertanyaan itu (Irwan, 2008:94-98). Ciriciri kalimat tanya parsial adalah mempergunakan kata tanya tertentu, misalnya: siapa, mengapa, apa, bagaimana, dll. Sama halnya dengan kalimat total, kalimat parsial juga bisa menggunakan partikel - kah, kecuali pada kata tanya mengapa tidak dapat menggunakan partikel $-k a h$.

(3) Kalimat tanya retorik, yaitu kalimat tanya yang tidak memerlukan jawaban atau tidak mengharuskan ada jawaban. Kalimat tanya retorik cenderung bersifat pernyataan hanya untuk mencari perhatian atau bermaksud memberi semangat, gugahan atau kritik. Kalimat tanya retorik sering digunakan dalam pidato-pidato atau orasi (Irwan, 2008:9498). Ciri--ciri kalimat tanya retorik: (a) berbentuk pertanyaan dan penegasan, terkadang mengunakan kata tanya, (2) tidak memerlukan jawaban, (3) orang yang bertanya dan yang ditanya samasama mengetahui jawabannya.

(4) Kalimat tanya tersamar, yaitu kalimat yang berisi pertanyaan yang diajukan secara tidak langsung bukan untuk menggali informasi, klarifikasi dan konfirmasi melainkan mengandung maksud-maksud lain (Irwan, 2008:9498).

\section{Bahasa Hukum}

Bahasa dan hukum kedua hal tersebut merupakan disiplin ilmu yang berbeda. Akan tetapi antara bahasa dan hukum tidak dapat dipisahkan (Wydick 1998). Hakim yang bertugas memeriksa dan mengadili suatu perkara yang dipimpin, harus menggunakan bahasa sebagai media untuk memperoleh informasi sejelas-jelasnya mengenai perkara tersebut. Begitu juga dengan perumus kebijakan haruslah menguasai bahasa, seperti ejaan, diksi, kalimat, dan paragraf agar produk hukum yang dihasilkannya dapat dipahami oleh orang banyak. Korelasi antara bahasa dan hukum merupakan suatu pertalian yang tidak dapat dipisahkan. Hal ini dapat diamati banyak pengacara yang menghabiskan waktunya untuk menulis dan berbicara (Tiersma 1999) untuk perkara yang ia tanggani.

\section{METODE PENELITIAN}

Metode yang digunakan dalam penelitian ini adalah metode deskriptifkualitatif. Data berupa transkrip percakapan persidangan dari Pengadilan Negeri Banda Aceh. Pengumpulan data menggunakan teknik simak-catat. Instrumen yang digunakan dalam penelitian sederhana ini selain peneliti sendiri, juga digunakan tape recorder untuk merekam selama terjadinya proses komunikasi dalam persidangan, dan alat pencatat yang digunakan setelah perekaman berlangsung. Penganalisisan data penelitian ini menggunakan analisis kontekstual dengan metode padan pragmatik. Metode padan pragmatik digunakan untuk menguraikan komponen tutur pada kalimat tanya sehingga dapat ditentukan jenis dan 
fungsi tindak tutur yang terkandung dalam tuturan tanya.

\section{HASIL DAN PEMBAHASAN}

\section{Data 1}

\begin{tabular}{|l|c|l|}
\hline $\begin{array}{l}\text { Nama } \\
\text { Perkara }\end{array}$ & $:$ & 88/Pdt.P/2017/PN Bna \\
\hline $\begin{array}{l}\text { Jenis } \\
\text { Perkara }\end{array}$ & $:$ & $\begin{array}{l}\text { Perbaikan Kesalahan } \\
\text { dalam Akta Kelahiran }\end{array}$ \\
\hline Pemohon & $:$ & $\begin{array}{l}\text { Irwani Fajriah binti } \\
\text { Umar }\end{array}$ \\
\hline $\begin{array}{l}\text { Hari \& } \\
\text { Tanggal } \\
\text { Sidang }\end{array}$ & $:$ & Selasa, 23 Mei 2017 \\
\hline Agenda & $:$ & Sidang Pertama \\
\hline $\begin{array}{l}\text { Ruang } \\
\text { Sidang }\end{array}$ & $:$ & $\begin{array}{l}\text { Ruang Sidang Utama } \\
\text { (Chandra) }\end{array}$ \\
\hline
\end{tabular}

Hakim : Sidang dengan nomor perkara 88/Pdt.P/2017/PN Bna dinyatakan dimulai dan dibuka untuk umum. (Suara ketukan palu tiga kali)

Hakim :Pemohon atas nama Irwani Fajriah benar? Ada masalah apa?

Pemohon : Begini Pak, di akta kelahiran tertulis saya lahir tahun 1990 di Banda Aceh, padahal saya lahir 1998 dan di kota Sabang.

Hakim : Ada bawa akta yang telah dilegalisasi biar saya lihat?

Pemohon : Maaf Pak, tidak saya bawa. Aktanya tinggal di asrama.

Hakim : Asrama mana? Kalau KK yang asli ada bawa?

Pemohon : Asrama Sabang. Ini Pak (maju ke meja hakim dengan membawa $\mathrm{KK}$ )

Hakim : Itu di sebelahnya ibu kandung ya?

Pemohon : Benar Pak.

Hakim : Mengapa harus diubah aktanya?

Pemohon : Saya mau kuliah.

Hakim : Baiklah. Untuk keterangan awal saya rasa sudah cukup. Selanjutnya, pemohon silakan bekomunikasi dengan panitera mengenai jadwal sidang selanjutnya. Dengan ini sidang dinyatakan ditutup. (ketukan palu tiga kali)

\section{Analisis dan Deskripsi Data}

(1) Hakim : (1a) Pemohon atas nama Irwani Fajriah, benar?

(1b) Ada masalah apa?

Pemohon : Begini Pak, di akta kelahiran tertulis saya lahir tahun 1990 di Banda Aceh, padahal saya lahir 1998 dan di kota Sabang.

Informasi Indeksial:

Tuturan tanya (1a) merupakan kalimat tanya konfirmasi yang ditandai dengan kata benar? Penggunaan kalimat tanya konfirmasi pada tuturan tanya (1a) bertujuan untuk memperjelas identitas Mt (Mitra Tutur) sebagai Pemohon atas nama Irwani Fajriah. Hal ini sesuai dengan teori bahwa kalimat tanya konfirmasi merupakan kalimat tanya untuk penjernihan yang disampaikan kepada orang lain dengan maksud mengukuhkan dan memperjelas persoalan yang sebelumnya telah diketahui oleh penanya (Bahri, 2017). Tuturan tanya (1a) juga dapat disebut sebagai kalimat tanya retorik karena hanya berupa penegasan sehingga kalimat tanya tersebut tidak mengharuskan adanya jawaban dari Mitra. Kalimat tanya retorik cenderung bersifat pernyataan hanya untuk mencari perhatian, gugahan, kritik, atau penegasan yang tidak memerlukan jawaban atau tidak mengharuskan ada jawaban (Irwan, 2008:9498).

Tuturan (1a) jika dikaitkan dengan konsep tindak tutur Searle, termasuk pada jenis tindak tutur representatif. Tuturan tanya (1a) dituturkan sesungguhnya bukan untuk meminta informasi tentang sesuatu, tetapi hanya digunakan untuk menyatakan penegasan mengenai identitas Mt. respon yang muncul dengan fungsi yang demikian dapat berupa jawaban benar atau hanya bentuk bahasa nonverbal (anggukan kepala). Pada tuturan tersebut, Mt menggunakan bahasa nonverbal.

Tuturan tanya (1b) merupakan kalimat tanya parsial yang bertujuan untuk meminta informasi. Kalimat tanya parsial merupakan 
kalimat tanya yang hanya meminta informasi sebagian dari pertanyaan itu (Irwan, 2008:9498). Pada tuturan (1b), kata tanya apa menggantikan objek kalimat yang kemudian dipindahkan ke depan. Ada pula pemakaian lain dari kedua kata itu yakni untuk menggantikan subjek kalimat (Alwi, dkk., 2003:361).Tuturan tanya (1b) merupakan fungsi tuturan representatif. Namun berbeda dengan tuturan tanya(1a) yang tidak memerlukan jawaban, pada tuturan tanya (1a) Mt diharuskan untuk memberikan jawaban dengan jelas karena jawaban Mt merupakan informasi yang diperlukan dalam proses persidangan. Oleh karena itu, fungsi representatif pada tuturan tanya (1a) ialah merepresentasikan pernyataan (dalam hal ini yaitu masalah yang dialami Mt sebagai pemohon). Pernyataan Mt berupa klarifikasi mengenai tahun lahir yang tertulis di akta.

Hakim : (1c) Ada bawa akta yang telah dilegalisir biar saya lihat?

Pemohon : Maaf Pak, tidak saya bawa. Aktanya tinggal di asrama.

Informasi indeksial:

Berdasarkan reaksi jawaban yang diharapkan, tuturan tanya (1c) merupakan kalimat tanya yang meminta keterangan mengenai akta Mt. Hal ini sesuai dengan konsep kalimat tanya Chaer (2006:350) yang menyatakan bahwa salah satu jenis kalimat tanya yang didasarkan atas reaksi jawaban yang diharapkan yaitu kalimat tanya yang meminta keterangan mengenai salah satu unsur kalimat. Tuturan tersebut juga termasuk dalam kalimat tanya tersamar. Pada tuturan tanya(1c) Pn mengharapkan Mt untuk memperlihatkan akta kelahiran Mt, tetapi Mt tidak membawa akta tersebut dengan alasan akta tersebut tertinggal di asrama.

Tuturan tanya (1c) mengandung fungsi tuturan direktif yang tergambar jelas pada tuturan biar saya liat. Pn menanyakan kepada Mt apakah Mt membawa akta kelahiran dengan maksud lain agar Mt memperlihatkan akta tersebut dan Pn dapat melihat kebenaran dari apa yang telah dijelaskan oleh Mt. Tindak direktif adalah tindak yang mengandung maksud menyuruh seseorang melakukan sesuatu; misalnya mengajak, perintah, permintaan, instruksi, dan lain-lain (Lindawati, 2012:261). Tuturan tanya(1c) mengandung maksud untuk meminta melalui tuturan Ada bawa akta yang dilegalisasi? Permintaan disampaikan secara tersamar atau tidak langsung, sekaligus juga mengandung maksud perintah melalui tuturan biar saya lihat.

Hakim : (1d) Asrama mana? (1e) Kalau KK yang asli ada bawa?

Pemohon: Asrama Sabang. Ini Pak (maju ke meja hakim dengan membawa KK) Informasi indeksial

Tuturan tanya (1d) merupakan kalimat tanya parsial dengan menggunakan kata tanyamana yang merujuk pada lokasi asrama Mt. Kata tanya mana menggantikan objek kalimat yang kemudian dipindahkan ke depan. Jika mana dipindahkan ke depan, seluruh konstruksi kalimat berubah menjadi Di mana asramanya? Penempatan mana pada awal kalimat mengakibatkan dua hal: (1) memunculkan preposisi di sebelum kata mana dan (2) memunculkan kata penujuk -nya. Pada umumnya kalimat tanya yang digunakan dalam bahasa hukum ialah kalimat yang singkat dan jelas. Oleh karena, Pn menggunakan kalimat tanya yang lebih ringkas seperti pada tuturan tanya(1d).

Tuturan tanya(1d) bertujuan untuk menggali informasi Mt, dengan fungsi yang demikian, respon yang muncul berupa pernyataan dari Mt. Adapun fungsi tuturan (1d) tersebut ialah fungsi tindak representatif.Pada tuturan (1d) Mt menjawab asrama Sabang yang menunjukkan suatu pernyataan mengenai lokasi asramanya.

Tuturan tanya(1e) merupakan kalimat tanya yang meminta keterangan mengenai kartu keluarga (KK) Mt. Hal ini sesuai dengan konsep kalimat tanya Chaer (2006) yang menyatakan bahwa salah satu jenis kalimat tanya yang didasarkan atas reaksi jawaban yang diharapkan yaitu kalimat tanya yang meminta keterangan mengenai salah satu unsur kalimat (hlm. 350). Tuturan tersebut juga termasuk dalam kalimat tanya tersamar karena mengandung lebih dari satu maksud. 
Pada tuturan (1e), Pn tidak hanya sekadar bertanya mengenai KK Mt, tetapi secara tidak langsung Pn juga menyuruh atau memerintahkan Mt untuk memperlihatkan KK tersebut. Kalimat tanya tersamar merupakan bentuk kalimat tanya yang mengacu pada bermacam maksud, pada intinya, seseorang yang member pertanyaan tidak menerangkan secara keseluruhan maksud dari pertanyaannya melainkan sebuah kode bagi si penjawab untuk dapat merespon maksud tersamar dari pemberi soal (Bahri, 2017).

Fungsi tuturan tanya(1e) adalah fungsi tindak direktif berupa maksud menyuruh. Tindak direktif adalah tindak yang mengandung maksud menyuruh seseorangmelakukan sesuatu (Lindawati, 2012:261). Pn menanyakan kepada Mt apakah Mt membawa Kartu Keluarga dengan maksud agar Mt memperlihatkan KK tersebut pada Mt. respon dari Mt terhadap pertanyaan Pn ialah maju ke meja hakim dengan membawa KK untuk diperlihatkan pada Mt.

Hakim : (1f) Itu di sebelahnya ibu kandung $y a$ ?

Pemohon : Benar Pak.

Informasi indeksial

Tuturan tanya (1f) termasuk dalam jenis kalimat tanya konfirmasi. Pn mengajukan pertanyaan tersebut untuk mengonfirmasi hubungan antara Mt dan seseorang yang berada di sebelahnya. Jawaban untuk jenis kalimat tanya konfirmasi dapat hanya berupa iya/benar atau tidak. Kalimat tanyakonfirmasi pada tuturan (1f) diperjelas dengan kata ya? oleh Pn. Kata ya? menandakan bahwa sebenarnya Pn sudah mengetahui jawaban dari persoalan yang ditanyakan.

Adapun fungsi tuturan tanya (1f) ialah fungsi tindak representatif. Sama halnya dengan konsep kalimat tanya konfirmasi, tindak representatif pada tuturan (1f) juga bertujuan untuk memperjelas atau mempertegas informasi yang telah diketahui oleh Pn. Respon yang muncul dengan fungsi representatif berupa pernyataan ini dapat berupa jawaban yang menyatakan pengiaan atau penidakan.

Hakim : (1g) Mengapa harus diubah aktanya?

Pemohon : Saya mau kuliah.

Informasi indeksial

Tuturan tanya (1g) termasuk dalam jenis kalimat tanya parsial yang bertujuan untuk meminta informasi dari Mt. Kata tanyamengapa digunakan untuk menanyakan sebab terjadinya sesuatu (Irwan, 2008:95). Pada tuturan (1g) Pn bertanya mengenai alasan atau maksud Mt ingin mengubah data pada akta kelahirannya. Tuturan tanya tersebut merupakan fungsi tindak representatif. Pada tuturan tanya(1g), Mt diharuskan untuk memberikan jawaban dengan jelas karena jawaban Mt merupakan informasi penting yang diperlukan dalam proses persidangan. Oleh karena itu, fungsi representatif pada tuturan tanya (1g) ialah merepresentasikan pernyataan (dalam hal ini yaitu maksud atau alasan Mt ingin mengubah akta kelahirannya).

\section{Data 2}

\begin{tabular}{|c|c|c|}
\hline $\begin{array}{l}\text { Nomor } \\
\text { Perkara }\end{array}$ & : & 16/Pdt.G/2017/PN Bna \\
\hline $\begin{array}{l}\text { Jenis } \\
\text { Perkara }\end{array}$ & : & Ganti rugi \\
\hline Pihak & : & $\begin{array}{l}\text { 1.Tuan Muhammad } \\
\text { Yusuf } \\
\text { 2.Notaris PPAT NADIA } \\
\text { SH MKn } \\
\text { 3.Badan Pertanahan } \\
\text { Kota Banda Aceh }\end{array}$ \\
\hline $\begin{array}{l}\text { Hari \& } \\
\text { Tgl. } \\
\text { Sidang }\end{array}$ & : & Senin, 4 Juli 2017 \\
\hline Agenda & & $\begin{array}{l}\text { bukti surat tambahan } \\
\text { dari tergugat dan saksi } \\
\text { dari penggugat }\end{array}$ \\
\hline $\begin{array}{l}\text { Ruang } \\
\text { Sidang }\end{array}$ & : & Ruang Sidang Cakra \\
\hline
\end{tabular}

Hakim : Kita mulai ya! Sidang perkara perdata16/Pdt.G/2017/PN

Bnadibuka dan dinyatakan terbuka untuk umum (Hakim 
mengetuk palu satu kali). Dari penggugat hadir, tergugat 1 , tergugat 2 hadir. Sesuai dengan acara hari ini agendanya adalah mendengarkan bukti surat tambahan dari tergugat dan saksi dari penggugat.

(2a) Bagaimana dari tergugat?

Tergugat 1: Sebelumnya yang asli lagi dibawa.

Hakim : (2b) Oh gitu, masih lama?

Tergugat 1 : Gak, Sedang menuju kemari.

Hakim : (2c) Itu sudah dileges?

Tergugat 1 : Sudah dileges.

Hakim : (2d) Bagaimana penggugat?

Penggugat : Hari ini kami datangkan saksi dua orang.

Hakim : (2e) Yang dileges ada dibawa?

Tergugat 1 : Ada ini.

Hakim : (2f) Ini satu aja?

Tergugat 1 : Iya

Hakim : (2g) Yang itu tidak ada yang asli?

Tergugat 1 : Aslinya ada sama penggugat. Kami mohon majelis memberikan waktu sebentar hingga kami membawa dokumen yang asli, karena pemberi kuasa tidak memberikan dokumen tersebut kepada kami dan katanya akan diberikan pada sidang berikutnya.

Hakim : (2h) Kapan bisa dibawa yang aslinya Pak?(2i) Sidang berikutnya bisa?

terugat 1 : Sidang berikutnya bisa. Kami mohon waktu sekali lagi kepada majelis.

Hakim : Kita periksa dulu identitasnya.

Hakim : (2j) Bersediakah jadi saksi Pak?

Saksi : Bersedia.

Hakim : (2k) Disumpah pak ya?(21) Selanjutnya saudara saksi 2 lahir di mana?

Saksi 2 : Banda Aceh

Analisis dan Deskripsi Data
Hakim : (2a) Bagaimana dari tergugat?

(2d) Bagaimana penggugat?

\section{Informasi indeksial}

Tuturan tanya (2a) dan (2d) merupakan jenis kalimat tanya parsial yang bertujuan untuk menanyakan keadaan atau cara melakukan perbuatan. Pada kedua tuturan di atas, $\mathrm{Pn}$ bertanya pada $\mathrm{Mt}_{1}$ dan $\mathrm{Mt}_{2}$ mengenai bukti surat tambahan dan saksi. Kata tanyabagaimana dimaksudkan Pn untuk menanyakan kejelasan bukti surat tersebut pada $\mathrm{Mt}_{1}$ dan $\mathrm{Mt}_{2}$. Melalui kata tanya bagaimana, diharapkan Mt dapat menjelaskan hal yang dimaksud Pn secara lugas dan jelas.

Tuturan tanya (2a) dan (2d) dikategorikan sebagai fungsi tuturan representatif. Tindak representatiftermasuk tindak yang merepresentasikan sesuatu; misalnya pernyataan, deskripsi, dan lain-lain (Lindawati, 2012:260). Jika diamati, jawaban dari pertanyaan Pn seharusnya dijawab dalam bentuk sebuah pernyataan atau pendeskripsian bukti dan saksi yang dimaksud. Hal ini dikarenakan hal yang ditanyakan adalah bagaimana bukti surat tambahan dari tergugat dan saksi dari penggugat. Namun, Pn menggunakan pertanyaan yang lebih ringkas dengan melesapkan unsur keterangan (bukti surat tambahan dan saksi) karena telah dijelaskan pada pernyataan Pn sebelumnya. Inilah salah satu ciri khas bahasa hukum, yaitu menggunakan bahasa yang singkat, jelas, dan lugas.

Hakim : (2b) Oh gitu, masih lama?

(2c) Itu sudah dileges?

(2e) Yang dileges ada dibawa?

(2f) Ini satu aja?

(2g) Yang itu tidak ada yang asli?

Informasi indeksial

Tuturan tanya (2b), (2c), (2e), (2f), dan (2g) merupakan jenis kalimat tanya total karena pertanyaan-pertanyaan tersebut dapat dijawab dengan tidak lebih dari satu kata, 
seperti (2b) tidak, (2c) sudah, (2e) ada, (2f) iya, (2g) ada. Pada umumnya, kalimat tanya total yaitu kalimat tanya yang meminta informasi mengenai seluruh isi pertanyaannya. Ciri-ciri kalimat tanya total ialah dapat menggunakan partikel $-k a h$ dan jawaban menggunakan "ya" atau "tidak" (Irwan, 2008:94-98). Pertanyaan seperti pada Tuturan tanya (2b), (2c), (2e), (2f), dan (2g) berupa kalimat interogatif dengan mempertahankan urutan kalimatnya, seperti urutan kalimat deklaratif, tetapi dengan intonasi yang berbeda.

Fungsi tuturan (2b) termasuk dalam fungsi tindak direktif yang menyatakan perintah. Pertanyaan itu ditujukan kepada Mt yang mengatakan bahwa bukti surat tambahan yang asli sedang dibawa menuju ke ruang persidangan. Kalimat tanya masih lama? mengisyaratkan pada Mt agar Pn tidak terlalu lama menunggu sehingga akan memakan waktu atau secara tersamar, Pn memerintahkan agar bukti surat tersebut secepatnya dibawa.Tuturan tanya (2e) dan $(2 \mathrm{~g})$ juga termasuk fungsi tuturan direktif karena selain bertujuan untuk memastikan sesuatu juga mengandung perintah untuk memperlihatkan hal yang dimaksud. Pada tuturan tanya (2e) dan (2g), Pn menyanyakan surat yang dileges dan surat yang asli. Pn berharap Mt merespon pertanyaannya dengan membawakan surat-surat tersebut ke hadapannya. Sementara itu, pada tuturan tanya (2c) dan (2f) termasuk fungsi tuturan representatif karena jawaban berupa suatu pernyataan atas apa yang ditanyakan Pn.

Hakim : (2h) Kapan bisa dibawa yang aslinya Pak?(2i) Sidang berikutnya bisa?

Hakim : (2j) Bersediakah jadi saksi Pak?

Informasi indeksial

Tuturan tanya (2h) merupakan jenis kalimat tanya parsial yang menggunakan kata tanya kapan yang merujuk pada waktu kapan Mt dapat membawa bukti surat yang asli. Sementara pada tuturan tanya (2i) kalimat tanya yang digunakan adalah kalimat tanya total. kalimat tanya total yaitu kalimat tanya yang meminta informasi mengenai seluruh isi pertanyaannya. Ciri-ciri kalimat tanya total ialah dapat menggunakan partikel $-k a h$ danjawaban menggunakan "ya" atau "tidak" (Irwan, 2008:94-98).

Tuturan tanya (2i) dan (2j) termasuk jenis kalimat tanya total karena jawabannya berupa bisa atau tidakdan bersedia atau tidak. Pada tuturan (2j), kalimat tanya total diperjelas dengan penggunaan partikel $-k a h$ pada kata bersediakah. Fungsi partikel -kah ialahmenjadikan kalimat lebih formal dan sedikit lebih halus.Partikel $-k a h$ ditambah pada partikel penanya itu untuk mempertegas pertanyaan itu. Intonasi yang dipakai dapat sama dengan intonasi kalimat berita.Apabila dipakai dalam kalimat tidak kata tanya tetapi intonasinya adalah intonasi interogratif, maka - kah akan memperjelas kalimat itu sebagai kalimat interogatif (Alwi, 2003:307-308).

Tuturan tanya (2i) juga dapat menggunakan partikel $-k a h$, tetapi akanada perubahan struktur kalimat. Partikel $-k a h$ dapat dilekatkan pada kata bisa sehingga struktur kalimatnya akan berubah menjadi Bisakah dibawa pada sidang berikutnya?. Ketiadaan partikel -kahpada tuturan (2i) akan membuat tuturannya menjadi lebih ringkas, sesuai dengan ciri bahasa hukum.

Fungsi tuturan (2h) ialah fungsi tindak representatif karena maksud tuturan tanya itu merepresentasikan sesuatu. Kalimat tanya yang dituturkanuntuk merepresentasikan sesuatu itusecara bersamaan dapat berfungsi fatis untuk meminta Mt memberikan pernyataan mengenai keterangan waktu (kapan surat asli dapat dibawa). Sementara itu, fungsi tuturan tanya(2i) ialah fungsi tindak direktif. Fungsi tindak direktif mengandung maksud menyuruh orang lain melakukan sesuatu. Tuturan (2i) mengandung maksud lain, selain untuk meminta kejelasan dari Mt mengenai kepastian untuk dapat membawa bukti surat tersebut, Pn melalui tuturan tanyanya juga secara tidak langsung menyuruh Mt untuk membawa bukti surat itu pada sidang berikutnya.

Tuturan tanya $(2 \mathrm{j})$ mengandung fungsi tuturan tindak direktif berupa meminta. Kalimat tanya dapat difungsikan untuk 
menyatakan permintaan. Arti kata meminta dalam bahasa Indonesia cukup banyak, seperti: berharap-harap agar diberi atau mendapat sesuatu, mempersilakan, meminang, dan memerlukan (Lindawati, 2012:262). Kalimat tanya yang difungsikan untuk meminta di sini seperti $(2 \mathrm{j})$ berarti berharap agar Mt bersedia menjadi saksi. Kalimat tanya (2j) diujarkan sesungguhnya bukan mempertanyakan kesediaan Mt untuk melakukan sesuatu yang dinyatakan dalam kalimat tanya. Penanya sudah yakin petanya mampu melakukan hal yang dinyatakan dalam kalimat tanya itu. Kalimattanya (2j) sesungguhnya difungsikan untuk menyatakan suruhan.

Hakim: (2k) Disumpah pak ya? (2l) Selanjutnya saudara saksi 2 lahir di mana?

Informasi indeksial

Tuturan tanya (2k) merupakan jenis kalimat tanya retorik karena tidak memerlukan jawaban. Kalimat tanya retorik ialah kalimat tanya yang tidak memerlukan jawaban atau tidak mengharuskan ada jawaban. Kalimat tanya retorik cenderung bersifat pernyataan hanya untuk mencari perhatian atau memperjelas maksud, gugahan atau kritik (Irwan, 2008:94-98). Pada tuturan tanya (2k), Pn hanya memberikan instruksi untuk melakukan sesuatu. Penggunaan kalimat tanya dalam memberikan instruksi bertujuan agar terkesan lebih halus dan sopan. Sementara itu, pada tuturan tanya (21), Pn menggunakan kalimat tanya parsial dengan kata tanyadi mana. Kata tanyadi mana bersifat manasuka. Seperti yang diutarakan Ramlan (2001:37-41) bahwa kata tanya siapa, apa, dimana, bagaimana terletak di depan kalimat ataupun di belakang kalimat, sedangkan kata tanya mengapa dan kapan teletak di depan kalimat.

Fungsi tuturan tanya (2k) ialah fungsi tindak direktif memaksa. Kalimat tanya yangdifungsikan untuk memaksa adalah kalimattanyayangdituturkanagarlawantuturm elakukan apa yang diharapkan penutur. Tuturan tanya (2k) adalah kalimat tanya yang dituturkan untuk memaksa Mt melakukan sesuatu yang diperintahkan oleh Pn. Tuturan tanya seperti (2k) berfungsi untuk menyatakan pemaksaan karena dituturka oleh seseorang yang status sosialnya lebih tinggi kepada orang yang status sosialnya lebih rendah. Penggunaan kata ya? bertujuan agar tindak direktif memaksa lebih terkesan sedikit halus.

Tuturan tanya (2l) termasuk jenis kalimat tanya representatif karena merepresentasikan sesuatu yaitu berupa pernyataan. Pn bermaksud menggali informasi mengenai tempat lahir Mt. Mt menjawab pertanyaan itu dengan bentuk pernyataan. Kalimat tanya yang dituturkan untuk merepresentasikan sesuatu itu secara bersamaan dapat berfungsi fatis untuk menegaskan informasi yang sebenarnya sudah diketahui Pn.

\section{Data 3}

\begin{tabular}{|l|l|l|}
\hline $\begin{array}{l}\text { Nomor } \\
\text { Perkara }\end{array}$ & $:$ & 179/Pid.B/2017/PN Bna \\
\hline $\begin{array}{l}\text { Jenis } \\
\text { Perkara }\end{array}$ & $:$ & Pencurian \\
\hline Terdakwa & $:$ & $\begin{array}{l}\text { Moehammad Iqbal bin } \\
\text { Asmuni }\end{array}$ \\
\hline $\begin{array}{l}\text { Hari \& Tgl. } \\
\text { Sidang }\end{array}$ & $:$ & Selasa, 11Juli 2017 \\
\hline Agenda & $:$ & Sidang Pertama \\
\hline $\begin{array}{l}\text { Ruang } \\
\text { Sidang }\end{array}$ & $:$ & $\begin{array}{l}\text { Ruang Sidang Utama } \\
\text { (Chandra) }\end{array}$ \\
\hline
\end{tabular}

Hakim : Sidang perkara pidana nomor 179/Pid.B/2017/PN Bna dibuka dan dinyatakan terbuka untuk umum (ketukan palu tiga kali)

Hakim : (3a) Identitasnya muhammad Iqbal bin Rusli lahir di?

Terdakwa : Banda Aceh

Hakim : (3b) Pada tanggal?

Terdakwa : tanggal 20 tahun 1977

Hakim : Jenis kelamin laki-laki, bangsa Indonesia. (3c) Alamat di mana?

Terdakwa : Rawa Sakti Timur ...

Hakim : Itu ditangkap $24 \mathrm{Mei}$, ditahan

2 April. (3d) Saudara sehat?

Terdakwa : Sehat. 


\begin{tabular}{|c|c|}
\hline Hakim & $\begin{array}{l}\text { : (3e) Sehat ya, bisa ikut } \\
\text { persidangan? }\end{array}$ \\
\hline Terdakwa & : Bisa. \\
\hline Hakim & $\begin{array}{l}\text { : (3f) Sudah dengar saudara } \\
\text { jaksa baca dakwaan tadi? }\end{array}$ \\
\hline Terdakwa & : Sudah \\
\hline Hakim & $\begin{array}{l}:(3 \mathrm{~g}) \text { Atas dakwaan tersebut } \\
\text { apa sudah mengerti? }\end{array}$ \\
\hline Terdakwa & : Mengerti \\
\hline Hakim & $\begin{array}{l}: \text { (3h) Mengerti ya?(3i) Kira- } \\
\text { kira ada yang salah gak } \\
\text { dakwaannya? }\end{array}$ \\
\hline Terdakwa & : Gak. \\
\hline Hakim & $\begin{array}{l}\text { : (3j) Jadi gak ada keberatan } \\
\text { ya? Kalau gak ada keberatan } \\
\text { kita masuk pada pemeriksaan } \\
\text { saksi ya? (3k) Ada saksinya } \\
\text { saudara jaksa? }\end{array}$ \\
\hline Jaksa & $\begin{array}{l}\text { : Kami mohon waktu satu } \\
\text { minggu majelis. }\end{array}$ \\
\hline Hakim & : Hari Senin ya! \\
\hline Jaksa & : (31) Tanggal? \\
\hline Hakim & $\begin{array}{l}\text { : Tanggal 24. Sidang kita tunda } \\
\text { sampai dengan hari senin } \\
\text { tanggal 24 Juli } 2017 \text { dengan } \\
\text { agenda pemeriksaan saksi. } \\
\text { Sidang dinyatakan ditutup } \\
\text { (ketukan palu tiga kali) }\end{array}$ \\
\hline
\end{tabular}

Analisis dan Deskripsi Data

$\begin{array}{cl}\text { Hakim } & : \text { (3a) Identitasnya } \\ & \text { Muhammad Iqbal bin } \\ & \text { Rusli lahir di? } \\ \text { Hakim } & : \text { (3b) Pada tanggal? } \\ \text { Hakim } & : \text { (3d) Saudara sehat? } \\ \text { Hakim } & : \text { (3e) Sehat ya, bisa ikut } \\ & \text { persidangan? } \\ \text { Hakim } & : \text { (3f) Sudah dengar } \\ & \text { saudara jaksa baca } \\ \text { dakwaan tadi? } & \\ \text { Hakim } & : \text { (3i) Kira-kira ada yang } \\ \text { Hakim } & \text { salah gak dakwaannya? } \\ \text { Jaksa (3k) Ada saksinya } & \text { saudara jaksa? } \\ \text { (31) Tanggal? }\end{array}$

Tuturan tanya (3a), (3b), (3l) merupakan tuturan tanya parsial. Ciri-ciri kalimat tanyaparsial ialah menggunakan kata tanya tertentu, tetapi pada ketiga tuturan tanya tersebut, kata tanya dilesapkan. Pada tuturan tanya (3a) kata tanya yang dilesapkan ialah kata tanya mana, pada (3b) dan (3l) kata tanya yang dilesapkan adalah berapa. Pelesapan kata tanyaseringkali digunakan dalam bahasa hukum Indonesia (BHI) karena dalam BHI bahasa harus jelas, dapat dimengerti, singkat, padat, lugas, dan eksak karena menghindari kesamaran dan ketaksaan.

Tuturan tanya (3d), (3e), (3f), (3i), dan (3k) merupakan jenis kalimat tanya total. Kalimat tanya total dapat tergambar jelas pada jawaban dari pertanyaan yang berupa pengulangai salah satu kata dari kalimat tanya itu dan jawaban dapat juga berupa kata ya atau tidak. Jika dilihat dari bentuk pertanyaannya, jawaban dari kelima tuturan tanya tersebut dapat berupa sehat (pengulangan kata sehat dari pertanyaan Saudara sehat? pada tuturan tanya (3d)); bisa (penggulangan kata bisa dari pertanyaan bisa ikut persidangan? Pada tuturan tanya (3e));sudah (penggulangan kata sudah dari pertanyaan Sudah dengan saudara jaksa baca dakwaan tadi? pada tuturan tanya (3f)); gak (penggulangan kata gak pada pertanyaan Kira-Kira ada yang salah gak dakwaannya? pada tuturan tanya(3i)); dan ada (penggulangan kata ada dari pertanyaan $A d a$ saksinya Saudara Jaksa? pada tuturan tanya (3k)). Dalam bahasa hukum Indonesia, Jawaban pertanyaan dari Pn diharapkan ringkas, tetapi jelas.Pertanyaan seperti pada Tuturan tanya(3a), (3b), (3d), (3e), (3f), (3i), (3k), dan (3l) memiliki kesamaan yaitu berupa kalimat interogatif dengan mempertahankan urutan kalimatnya, seperti urutan kalimat deklaratif, tetapi dengan intonasi yang berbeda.

Tuturan tanya(3a), (3b), (3d), (3e), (3f), (3i), (3k), dan (3l) mengandung fungsi tuturan tindak representatif karena merepresentasikan pernyataan berupa informasi dari Mt. Tuturan (3a) dan (3b) merupakan pertanyaan yang menyangkut identitas Mt, sedangkan pada tuturan tanya (3d), perntanyaan diujarkan Pn untuk memberikan perhatian pada Mt dan sekaligus bertujuan untuk memastikan keadaan Mt apakah Mt bisa mengikuti persidangan dengan keadaannya yang 
sekarang (lihat tuturan (3e). Tuturan tanya (3f), (3i), (3k), dan (3l) berfungsi untuk memastikan dan menegaskan hal yang sebelumnya sudah disebutkan atau sudah diketahui oleh Pn dan Mt.

\section{Hakim : (3c) Alamat di mana? \\ Hakim : (3g) Atas dakwaan tersebut apa sudah mengerti?}

Informasi indeksial

Tuturan tanya (3c) merupakan kalimat tanya parsial dengan menggunakan kata tanya dimana yang merujuk pada alamat Mt. Pada tuturan tanya (3c) terdapat pronomina yang dilesapkan yaitu pronomina kamu (di mana alamat kamu?) Kata tanya mana jika dipindahkan ke depan mengakibatkan berubahnya konstruksi kalimat menjadi $d i$ mana (predikat) alamatmu (subjek)? Berdasarkan hal tersebut, terlihat bahwa bahasa hukum Indonesia, umumnya tidak mementingkan urutan pola kalimat, tetapi lebih mengutamakan keterpaduan makna (mudah dimengerti). Hal tersebut terlihat juga pada tuturan tanya $(3 \mathrm{~g})$ yang juga merupakan jenis kalimat parsial dengan memosisikan kata tanya apa di tengah kalimat.

Tuturan tanya (3c) dan (3g) mengandung fungsi merepresentasikan sesuatu. Kalimat tanya yang dituturkan untuk merepresentasikan sesuatu itusecara bersamaan dapat berfungsi fatis untuk menyebutkan dan menyatakan mengenai hal yang ditanyakan. Fungsi menyebutkan tergambar pada jawaban dari tuturan tanya (3c), sedangkan fungsi menyatakan tergambar pada jawaban dari tuturan tanya $(3 g)$.

$\begin{aligned} \text { Hakim } \quad: & (3 \mathrm{~h}) \text { Mengerti ya? } \\ \text { Hakim } & : \text { (3j) Jadi gak ada } \\ & \text { keberatan ya? Kalau } \\ & \text { gak ada keberatan kita } \\ & \text { masuk pada } \\ & \text { pemeriksaan saksi ya? }\end{aligned}$

Informasi indeksial

Tuturan tanya (3h) dan (3j) merupakan jenis kalimat tanya retorik karena tidak memerlukan jawaban. Kalimat tanya retorik cenderung bersifat pernyataan hanya untuk mencari perhatian, gugahan, kritik, atau penegasan yang tidak memerlukan jawaban atau tidak mengharuskan ada jawaban (Irwan, 2008:94-98). Pada tuturan tanya (3h) dan (3j), Pn hanya sekadar menanyakan persetujuan yang sebenarnya respon atau jawaban dari pertanyaan tersebut sudah diketahui Pn sehingga tidak memerlukan jawaban lagi dari Mt. Fungsi lain dari tuturan tanya (3h) dan (3j) ialah sebagai penegasan dari jawaban Mt pada pertanyaan sebelumnya.

Tuturan tanya(3h) mengandung fungsi representati. Pada tuturan (3h), Pn hanya sekadar mengulang jawaban dari Mt sebelumnya sebagai bentuk penegasan dari jawaban Mt.Sementara itu, pada tuturan (3j), Pn berharap dari pertanyaannya itu akan memunculkan jawaban dari Mt sesuai dengan yang diharapkannya yaitu Mt tidak keberatan dengan dakwaan yang sudah disebutkan sebelumnya. Tuturan tanya ( $3 \mathrm{j}$ ) mengandung tindak direktif yang berfungsi memerintahkan. Pn memerintahkan untuk masuk pada tahap pemeriksaan saksi (lihat tuturan (3j)). Pn menggunakan kata ya? di akhir pertanyaannya sebagai bentuk meminta persetujuan agar 'perintah' yang disebut terkesan halus. Berdasarkan hal tersebut, terlihat bahwa bahasa hukum Indonesia mempunyai gaya bahasa yang khusus, tidak beremosi dan menjauhi tafsiran bersensasi.

\section{PENUTUP \\ Simpulan}

Jenis kalimat yang terkandung dalam bahasa hukum Indonesia yaitu kalimat parsial, kalimat total, kalimat retorik, dan kalimat tersamar. Kalimat tanya yang paling dominan ditemukan adalah kalimat tanya parsial, sedangkan kalimat tanya yang paling sedikit ditemukan ialah kalimat tanya tersamar. Pada umumnya kalimat tanya yang digunakan dalam bahasa hukum ialah kalimat yang jelas, dapat dimengerti, singkat, padat, lugas, dan eksak karena menghindari kesamaran dan ketaksaan. Kalimat tanya dalam bahasa hukum Indonesia juga umumnya tidak mementingkan urutan pola 
kalimat, tetapi lebih mengutamakan keterpaduan makna.

Fungsi tuturan tanya yang banyak ditemukan ialah fungsi merepresentasikan pernyataan atau tuturan tindak representatif berupa penegasan dan pendeskripsian (barang bukti). Selain itu, fungsi tuturan lain yang banyak ditemukan ialah fungsi tuturan tindak direktif berupa perintah (menyuruh, instruksi) dan meminta. Hal tersebut tentunya sesuai dengan kegiatan pelaksanaan persidangan yang di dalamnya terdapat perintah-perintah tertentu dan permintaan yang berkaitan dengan kasus yang dibahas.

\section{Saran}

Diharapkan materi pragmatik berupa prinsip kerja sama diajarkan kepada

\section{DAFTAR PUSTAKA}

\section{Buku}

Alwi, Hasan, dkk. (2003). Tata Bahasa Baku Bahasa Indonesia. Jakarta: Balai Bahasa.

Austin, J.L. (1962). How To Do Thing With Words. London: Oxford University Press.

Chaer, Abdul dan Leoni Agustina. (2010). Sosiolinguitik Perkenalan Awal. Jakarta: PT Rineka Cipta

Chaer, Abdul. (2006). Tata Bahasa Praktis Bahasa Indonesia. Jakarta: Rineka Cipta.

Irwan, dkk. (2008). Bahasa Indonesia 2 untuk SMK/MAK Semua Program Keahlian. Jakarta: Pusat Pembukuan Departemen Pendidikan Nasional.

Leech, Geoffrey. (2011). Prinsip-Prinsip Pragmatik (diterjemahkan oleh OKA). Jakarta: Universitas Indonesia Press.

Martinich. A.P. (1996). The Philosphy of Language. New York: Oxford University Press.

Myška, M et al Eds. (2012). "Creative Commons and Grand Challenge to Make Legal Language Simple". In AI Approaches to the Complexity of mahasiswa Fakultas Hukum sebagai dasar menjadi praktisi hukum. Pembelajaran bahasa Indonesia pada perguruan tinggi, khususnya pada fakultas hukum tidak meniktikberatkan kebutuhan pada kebutuhan praktisi hukum. Oleh karena itu, perkuliahan bahasa Indonesia pada perguruan tinggi di Fakultas Hukum juga mempelajari kajian pragmatik dan fungsi kalimat tanya.

Penelitian ini merupakan penelitian awal dan tidak komprehensif. Diharapkan penelitian tindak lanjut berkaitan dengan fungsi kalimat tanya juga dilakukan, baik pada Pengadilan Agama, Pengadilan Tata Usaha Negara, maupun Pengadilan Militer. Hal ini bertujuan transiplin ilmu saling bermanfaat antara ilmu bahasa dan ilmu hukum. Hal ini disebabkan kedua bidang ilmu ini saling berkaitan.

Legal Systems.Springer Heidelberg Dordrecht London NewYork.

Nasution, Bahder Johan and Sri Wirjayati. (2001). Bahasa Indonesia Hukum. Bandung: PT Citra Aditya Bakti.

Ramlan. (2001. Ilmu Bahasa Indonesia: Sintaksis. Yogyakarta: CV. Karyono.

Searle. J. (1976). "A Classification of Illocutionary Act". Reprinted in D. Carbaugh (ed), 1990. Cultural Communication and Intercultural Contact. New Jersey: Lawrence Erlbaum

Tiersma, Peter M. (1999). Legal Language. London: The University of Chicago Pres, Ltd.

Wydick, Richard C. (1998). Plain English for Lawyer. Durham: North Carolina: Carolina Academic Press.

Yule, George. (2014). Pragmatik. Terjemahan oleh Indah Fajar. Yogyakarta: Pustaka Pelajar.

\section{Artikel}

Choukroune, L. (2016). The Language of Rights and the Politics of Law: Perspectives on China's Last Legal Ditch Struggle. Int J Semiot Law. Vol. 29, (779-803). 
Harjanti, W. (2010). "Bahasa Hukum Dalam Perspektif Rasionalisme (Legal Terminology in Rasionalism Perspective)". Risalah Hukum: Jurnal Hukum. Vol 6, No 1 (29-36).

Lindawati. (2012). "Fungsi Tutur Kalimat Tanya Bahasa Indonesia". JurnalLitera. Vol. 11, No.2, (256266).

Nuthihar, Rahmad and Denni Iskandar. "Karakteristik Ragam Bahasa
Hukum dalam Naskah Putusan Pengadilan Negeri Banda Aceh". Jurnal Kalkelpot. Vol. 5, No. 2, (5569).

\section{Internet}

Bahri, Syamsul. (2017). "Jenis-Jenis Kalimat Tanya dan Kata Tanya (Klarifikasi, Retoris, Tersamar, dan Biasa)". Online. www.padahakan.com. diakses 05 Oktober 2017. 